\title{
CHRONIC HYPOPARATHYROIDISM ASSOCIATED WITH A MULTICYSTIC KIDNEY
}

BY

\author{
R. G. MITCHELL \\ From the Royal Hospital for Sick Children, Edinburgh
}

(RECEIVED FOR PUBLICATION MARCH 28, 1954)

The criteria for diagnosis of chronic idiopathic hypoparathyroidism were laid down by Drake, Albright, Bauer and Castleman (1939) as (1) a low serum calcium level with a raised serum inorganic phosphorus level; (2) the exclusion of renal insufficiency as a cause of the hyperphosphataemia; (3) the presence of symptoms and signs of chronic tetany; and (4) the absence of radiological abnormality of the bones. Emerson, Walsh and Howard (1941), however, reported increased density of bone in a case of idiopathic hypoparathyroidism, and, with the first three of the above features, this is now considered to be characteristic of the condition.

The following case is considered to satisfy these criteria, and is of unusual interest because the patient's mother had hyperparathyroidism, and also because of the early age of onset and the associated renal anomaly.

\section{Case Report}

The patient was an only child and there was no family history of epilepsy or mental defect. He was born spontaneously on January 16, 1947, the birth weight being $11 \mathrm{lb}$., and he was breast fed for nine months. He sat up at 5 months, began talking at a year, and walked unassisted at 14 months.

At about 1 year of age it was noticed that whenever he cried he developed 'crowing' respirations, and four months later he had several generalized convulsions within a few days. He was admitted to hospital, where the stridor and convulsions were attributed to an infantile condition of the larynx. During the next two years he had only three fits and his general health was good, though he made little progress in speech and still had stridor when he cried or became excited. At 3 years and 4 months he began to have frequent episodes of staring into space, with slight twitching movements of the limbs lasting only a few seconds. A diagnosis of petit mal was made and treatment with 'tridione' was started, but no improvement occurred until phenobarbitone was added, when the 'turns' became less frequent.

At 3 years and 7 months he began to complain of pain in the feet during the 'turns' and had intermittent attacks of diarrhoea. He was admitted to the Royal
Hospital for Sick Children, Edinburgh, on August 22, 1950, for further investigation.

On admission the patient was a tall, well-nourished child, with an intermittent coarse tremor of the head and arms, especially noticeable on purposeful movement. His height was $39 \cdot 5$ in. $(100 \mathrm{~cm}$.) and his weight $41 \cdot 5 \mathrm{lb}$. $(19 \mathrm{~kg}$.). The skin and hair were a little dry but there was no abnormality of the teeth or nails.

No abnormality of the cranial nerves was found and examination of the eyes showed no cataract, no nystagmus, and normal fundi. His limbs were slightly spastic with easily elicited reflexes, equal on the two sides, and Chvostek's and Trousseau's signs were present.

Examination of the cardiovascular and respiratory systems revealed no abnormality; the blood pressure was $100 / 65 \mathrm{~mm}$. Hg.

The left kidney was not palpable but a smooth, mobile painless mass was felt in the position of the right kidney. The liver was of normal size and the spleen could not be felt.

His speech was unintelligible and his behaviour suggested a mental age of at least a year younger than his chronological age.

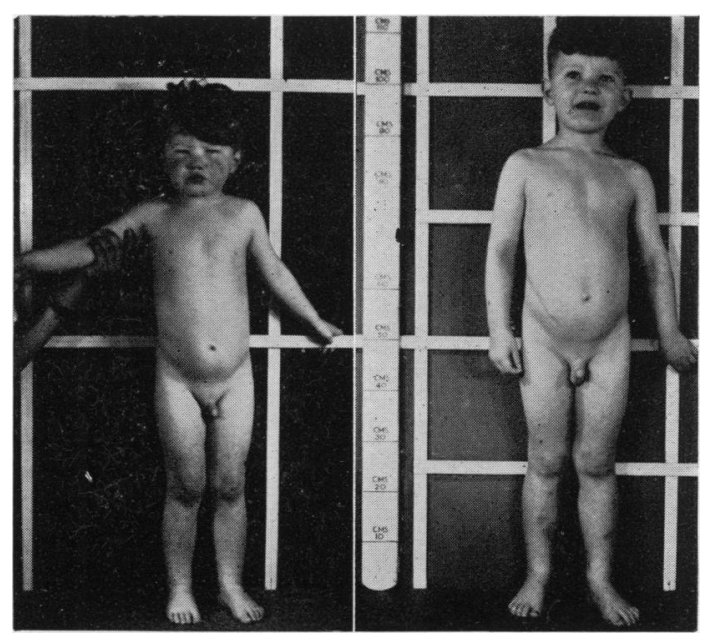

Fig. 1A.-The patient before treatment.
Fig. 1B.-One year later on maintenance treatment with calciferol. 
In the days following admission, he had frequent shaking attacks in which he screwed up his face and seemed unaware of his surroundings for about 30 seconds. He also had frequent painful spasms of the feet and two

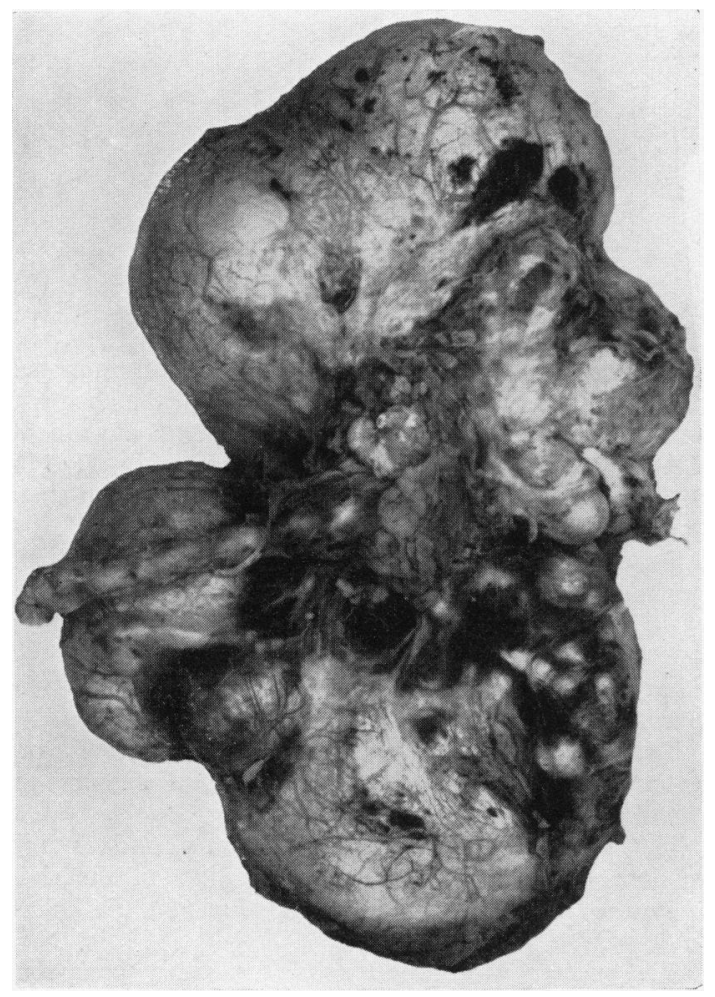

Fig. 2.-The right kidney (almost natural size).

episodes of generalized tetany with opisthotonos and laryngeal stridor.

Preliminary Investigations. The haemoglobin was $14 \mathrm{~g}$. \%, the leucocyte count 15,600 per c.mm., and the erythrocyte sedimentation rate $8 \mathrm{~mm}$. in one hour. Bleeding and clotting times were normal, and the blood urea nitrogen was $17 \mathrm{mg}$. \%. Estimations on serum showed calcium to be $3 \mathrm{mg}$. \%, inorganic phosphorus $7.2 \mathrm{mg}$. \%, chlorides $595 \mathrm{mg}$. \%, sodium $330 \mathrm{mg}$. \%, potassium $22 \mathrm{mg}$. \%, carbon dioxide-combining power 67 volumes \%, alkaline phosphatase 17 King-Armstrong units $\%$, albumin $5.38 \mathrm{~g}$. \% and globulin $1.95 \mathrm{~g} . \%$.

The $p \mathrm{H}$ of the urine was 5 and the specific gravity 1015 . A trace of albumin was present but no cells, and culture was sterile. The Sulkowitch test was negative.

Radiological examination showed a slight increase in density of bone in the pelvis and femur and no abnormality in the skull, chest or hand. A barium meal showed defective filling of the caecum, which was slightly displaced towards the midline.

No oral moniliasis was found on repeated examination.
A modified form of the parathyroid hormone sensitivity test (Ellsworth and Howard, 1934) was carried out, using one-quarter of the dose of parathyroid extract recommended for an adult. Three hourly specimens of urine were collected and then 50 units of parathyroid extract (i.e., 10 units of Lilly's parathormone) were injected intravenously, after which three further hourly specimens were collected. The results of this test are shown in the table and the rise in phosphorus excretion is considered sufficient to exclude the condition of pseudohypoparathyroidism described by Albright, Burnett, Smith and Parson (1942).

TABLE

PARATHYROID HORMONE SENSITIVITY TEST

\begin{tabular}{|c|c|c|c|}
\hline Time & $\begin{array}{l}\text { Fluid Intake } \\
\text { (ml.) }\end{array}$ & $\begin{array}{l}\text { Urine Volume } \\
\text { (ml.) }\end{array}$ & $\begin{array}{c}\text { Inorganic } \\
\text { Phosphorus } \\
\text { (mg.) }\end{array}$ \\
\hline 8-9 a.m. .. & 100 & 32 & $14 \cdot 7$ \\
\hline 9-10 a.m. .. & 100 & 28 & $12 \cdot 6$ \\
\hline 10-11 a.m... & 100 & 34 & $12 \cdot 0$ \\
\hline 11.05 a.m... & Intravenous in & $\begin{array}{l}\text { tion of } 50 \text { units } \\
\text { act in } 2 \mathrm{ml} \text {. sali }\end{array}$ & parathyroid \\
\hline 11 a.m.-12. & 100 & 31 & $44 \cdot 0$ \\
\hline $12-1$ p.m. .. & 100 & 148 & $35 \cdot 5$ \\
\hline 1-2 p.m. .. & 100 & 44 & $44 \cdot 0$ \\
\hline
\end{tabular}

Progress. A provisional diagnosis of idiopathic hypoparathyroidism was made and because of the severity of the symptoms, it was decided to treat this condition before further investigation of the abdominal tumour. Treatment was started on September 2 and consisted of 20,000 units of calciferol as liquor calciferolis (B.P.C.), 30 gr. of calcium lactate daily and a diet low in phosphorus. Two weeks later, the calciferol was increased to 40,000 units daily. On this regime, the serum calcium level slowly rose until on October 9 it was $7.6 \mathrm{mg}$. \%, with serum phosphorus $4.9 \mathrm{mg}$. \%. The Sulkowitch test showed a normal urinary excretion of calcium and all signs of tetany had disappeared.

As the child was now well and cheerful, an intramuscular pyelogram was carried out. This showed good concentration on the left side with a normal pelvis and ureter apart from small, cyst-like dilatations of several calyces, an appearance resembling that seen in hydrocalicosis. There was no shadow at all on the right silde. Cystoscopy showed that the bladder and left ureteric orifice were normal, while the right ureteric orifice was a crescentic slit through which a catheter could be passed only to $1 \mathrm{~cm}$.

An exploratory operation was carried out by Miss R. M. Mackay on November 10 . The right kidney was found to be completely replaced by a number of cysts, which were removed in one mass. Post-operative progress was uneventful.

Pathological Report. The specimen consisted of two large, one medium, and a large number of small cysts connected by fibrous tissue (Fig. 2). No normal renal 
tissue was seen. The ureter and pelvis appeared to communicate with the centre of the masss.

Microscopical sections showed numerous cysts of various sizes (Fig. 3). In some of the larger cysts the

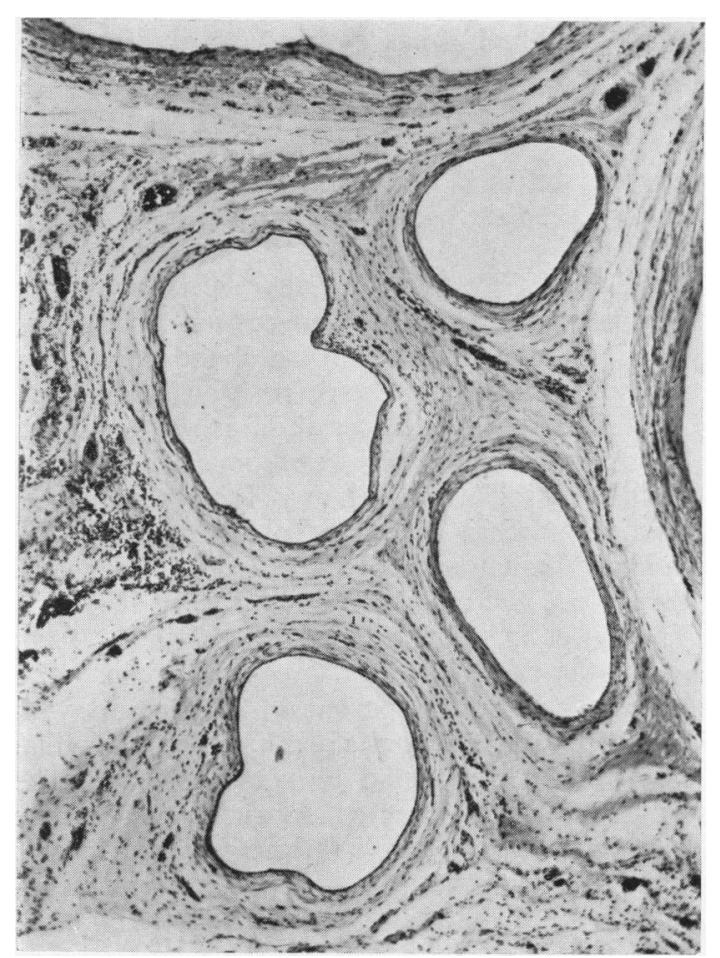

FIG. 3.-Photomicrograph showing cystic structure of kidney $\times 50$.

lining cells were flattened, while in others they were low, cubical cells with clear cytoplasm. In the smaller cysts the lining cells were cubical or flattened, always in only a single layer. The cysts were separated by a vascular fibrous stroma in which there were some small epithelial ducts, separately or in small groups. These were lined by small cubical or columnar cells, strongly basophilic. There were occasional groups of undifferentiated basophilic cells having the character of the primitive metanephric blastema, among which tiny tubules had begun to form. There were no normal renal tubules or glomeruli. No cartilage was found in the sections. The ureter had a thick wall, mostly fibrous with poorly developed muscle. The lumen was very minute and was lined by a single layer of small cubical cells.

Further Progress. One week after operation the child was very well and investigation showed the serum calcium level to be $9 \cdot 3 \mathrm{mg}$. \%, serum inorganic phosphorus $5.9 \mathrm{mg}$. \%, and blood urea nitrogen $14.5 \mathrm{mg}$. \%. He was discharged from hospital on November 21 to continue on calciferol, 40,000 units a day, with oral calcium lactate.

On January 5, 1951, the serum calcium and phosphorus levels had been within normal limits for two months, and it was decided to assess the effect of stopping treatment. Six weeks later, the serum calcium level had fallen to $6.4 \mathrm{mg}$. \%, the phosphorus level had risen to $6.6 \mathrm{mg}$. \%, and he began to have slight shaking attacks. Treatment was started again, and by June 12 a satisfactory maintenance dose of 50,000 units of calciferol (one high potency 'ostelin' tablet) daily had been established, which maintained the serum calcium level between 9 and $11 \mathrm{mg} . \%$, and the phosphorus level between 5 and $6 \mathrm{mg}$. \%.

During the ensuing three months, the blood urea nitrogen, which had been between 12 and $19 \mathrm{mg}$. \% since operation, rose to $24 \mathrm{mg}$. \%, and in view of this he was re-admitted on October 31 for urea clearance tests, which showed a standard clearance of $63 \%$ and $67 \%$ on two separate occasions. An intravenous pyelogram showed that the left kidney was functioning satisfactorily; there was no appreciable difference in the appearance of the calyces observed one year previously.

For the next 18 months the child was in good health and the blood urea nitrogen level remained at about $16 \mathrm{mg} . \%$. In June, 1953, the child's mother was found to have a parathyroid adenoma, and enquiry revealed that symptoms had been present during the pregnancy seven years previously. An attempt was made to replace maintenance therapy by implanting fragments of the adenoma into the child, but unfortunately the effects of the transplant lasted only a few weeks, and calciferol had to be resumed. Details of the mother will be reported elsewhere.

In January, 1954, the child was in good health on a maintenance dose of 50,000 units of calciferol daily with supplementary calcium lactate. The serum calcium level was $10.3 \mathrm{mg}$. \%, serum phosphorus $5.3 \mathrm{mg}$. \%, and blood urea nitrogen $16 \mathrm{mg}$. \%.

Other Investigations. An electrocardiogram before treatment showed a Q-T interval of 0.38 seconds at a heart rate of 110 per minute. By November 16, 1950, the Q-T interval had been reduced to 0.31 seconds at a heart rate of 125 per second, representing a reduction of about $16 \%$, calculated by Bazett's formula.

An electroencephalogram before treatment showed irregular slow activity of large amplitude (3-8 cycles per second) in both hemispheres, most marked posteriorly. A second examination after the patient had been on maintenance therapy for some months showed that the record was normal for his age.

Intelligence tests at the age of $4 \frac{1}{2}$ years gave him an I.Q. of 65. Further tests six months later showed that there had been slight improvement, his I.Q. being 70. At the age of 7 he is attending school and is in a class appropriate to his age; it appears likely that improvement will continue as long as adequate maintenance therapy is carried out.

\section{Discussion}

In most previous case reports, patients with idiopathic hypoparathyroidism have been treated as epileptics until the true nature of their condition has 
been recognized. Major epileptiform attacks have been most frequently observed but petit mal has also been reported (Eaton and Haines, 1939; Himsworth and Maizels, 1940). It has been suggested that the occurrence of epilepsy in hypoparathyroidism is purely coincidental (Taubenhaus and Engle, 1945) but the frequency of the association suggests a closer relationship, and it is probable that the excitability of the whole nervous system is increased by the hypocalcaemic state (Simpson, 1952).

The presence of renal disease is usually thought to exclude the diagnosis of idiopathic parathyroid hypofunction, which is based on the absence of other known causes of hyperphosphataemia. However, those cases of renal disease which resemble hypoparathyroidism clinically show other profound biochemical changes in the blood, and rapid deterioration eventually occurs. Renal damage may of course arise during the treatment of idiopathic hypoparathyroidism but then it is due to hypercalcaemia from excessive dosage of vitamin D (Brimblecombe, 1949).

A renal cause for the biochemical changes in the present case is considered to be excluded by the results of analysis of the urine, by the normal values for blood urea nitrogen and carbon dioxide combining power, and by the return to normal of the serum calcium and phosphorus levels following treatment.

The Cystic Kidney. Although the absence of function in the grossly abnormal right kidney and the good function in the left kidney, suggested that the condition was unilateral, the slight abnormality of the left pyelogram indicated the possibility that both kidneys were affected and made it important to determine the exact nature of the renal abnormality.

Polycystic disease is generally bilateral but Ravitch and Sanford (1949) reported a group of cases which differed from true polycystic disease and in which the cysts involved only one kidney. The authors used the term 'multicystic kidney' for this group and described four cases in infancy, with six similar cases from the literature. However, Powell, Shackman and Johnson (1951) pointed out that Ravitch and Sanford's collected cases were not a single group and that at least two were examples of multilocular cysts of the kidney. There are therefore at least three conditions in which the kidney contains numerous cysts (1) true polycystic disease; (2) multilocular cysts, in which many intracystic septa are present within one large cyst; and (3) multicystic kidneys, formed by a variety of cysts, which are completely separated by a fibrous stroma. The literature suggests that cystic kidneys of the second and third types are always unilateral.

Ravitch and Sanford thought that the multicystic kidney might be a type of teratoma, because of the occurrence of cartilage and abnormal tubular structures. Small areas of cartilage are, however, seen in non-teratomatous conditions such as nephroblastoma and renal hypoplasia, and it is more likely that the multicystic kidney is the result of a gross dysplasia of the metanephric blastema at an early stage (Macgregor, 1951).

Aetiology of the Hypoparathyroidism. Chronic idiopathic hypoparathyroidism appears to exist in two forms, one occurring in childhood and adolescence and the other in elderly people (Drake et al., 1939). The cause of the condition is unknown and more than one factor may be responsible while the occasional association with hypofunction of other endocrine glands is evidence that the action of the aetiological agent may be widespread (Himsworth and Maizels, 1940; Leonard, 1946).

The onset in early life of the childhood form suggests the possibility of a pre-natal origin. The condition has been reported in association with other congenital abnormalities, while a familial incidence has been noted by some authors. The family described by Sutphin, Albright and McCune (1943), in which there were three cases of idiopathic hypoparathyroidism, was also affected by a congenital blood dyscrasia. Lachmann (1941) reported a family of five siblings of whom three, and possibly four, had idiopathic hypoparathyroidism; the three affected children had associated abnormalities of the hands and feet, two of them showing partial syndactyly.

It seems possible that the condition in the present patient originated during intra-uterine life as the result of maternal hyperparathyroidism, which may have acted by preventing normal development of the foetal parathyroid glands or by suppressing the function of the formed glands. Such a result of a maternal parathyroid adenoma has been reported (Friderichsen, 1939) but the effect on the infant's glands was not permanent. The delay in onset of the symptoms may have been due to the low phosphate content of breast milk, since the first manifestations of tetany did not appear until shortly after breast feeding was stopped. The malformation of the kidney may also have been caused by hyperparathyroidism during the pregnancy.

\section{Summary}

The case of a child who had chronic hypoparathyroidism associated with a multicystic kidney is 
reported. It is suggested that maternal hyperparathyroidism was responsible for both conditions.

I thank Dr. D. N. Nicholson for permission to report this case and Dr. A. R. Macgregor for her help and criticism. I am indebted to Dr. J. A. Strong for allowing me to refer to the mother's case. I am most grateful to the biochemists of the Royal Hospital for Sick Children for assistance in the management of the patient.

REFERENCES

Albright, F., Burnett, C. H., Smith, P. H. and Parson, W. (1942) Endocrinology, 30, 922.

Brimblecombe, F. S. W. (1949). Archives of Disease in Childhood, 24, 77.
Drake, T. G., Albright, F., Bauer, W. and Castleman, B. (1939). Ann. intern. Med., 12, 1751.

Eaton, L. M. and Haines, S. F. (1939). J. Amer. med. Ass., 113, 749. Ellsworthy, R. and Howard, J. E. (1934). Bull. Johns Hopk. Hosp. 55,296

Emerson, K., Walsh, F. B. and Howard, J. E. (1941). Ann. intern. Med., 14, 1256.

Friderichsen, C. (1939). Lancet, 1, 85.

Himsworth, H. P. and Maizels, M. (1940). Lancet, 1, 959.

Lachmann, A. (1941). Acta med. scand., Supp. CXXI.

Leonard, M. F. (1946). J. clin. Endocr., 6, 493.

Macgregor, A. R. (1951). Personal communication.

Powell, T., Shackman, R. and Johnson, H. D. (1951). Brit. J. Urol., 23, 142 .

Ravitch, M. M. and Sanford, M. C. (1949). Pediatrics, 4, 769.

Simpson, J. A. (1952). Brain, 75, 76.

Sutphin, A., Albright, F. and McCune, D. J. (1943). J. clin. Endocr. 3, 625 .

Taubenhaus, M. and Engle, H. M. (1945). Ibid., 3, 147. 